\title{
Differences between Language and Linguistic in the ELT Classroom
}

\author{
Hajar Shahhoseiny \\ Bushehr Science and Research Branch, Islamic Azad University, Busheh, Iran
}

\begin{abstract}
This paper attempts to present differences between language and linguistic. Language and linguistic are two different words but there is relationship between them. 'Language' is a sign system of humankind in order to communicate one's thoughts, Feelings, and opinions to someone else but linguistic is scientific study of language. In fact the goal of linguistic is to describe languages and to explain the unaware knowledge all speakers have about their language. Therefore, linguistics is a subject of study that is built on languages. Noam Chomsky (1957) argues that "Language is a set (finite or infinite) of sentences, each finite in length, and constructed out of a finite set of elements" (p.13). According to Aronoff (2007) it is impossible to separate language from literature, or politics, or most of our everyday human interactions. "[Linguistics] has a twofold aim: to uncover general principles underlying human language, and to provide reliable descriptions of individual languages" (Aitchison, 1992). Also linguists, study individual human languages and linguistic behavior in order to discover the fundamental properties of this general human language.
\end{abstract}

Index Terms —-language, linguistic, differences between language and linguistic

\section{INTRODUCTION}

The beginning of the research of the relationship between linguistic theory and language teaching can be traced back to the late of 19th century. Until 1960s, when their relationship was reassessed, emerged two viewpoints: one was to say that linguistics is not so important as it has been thought, i.e. its importance had been overrated. Some linguists like Johnson (1967) and Lamendella (1969) expressed their disagreement to regard linguistics as the basis of a strategy of learning. Lamendella (1969) thought that it was a mistake to look to transformational grammar or any other theory of linguistic description to provide the theoretical basis for second language pedagogy. Levenson (1979) once said, "no one school of linguistic analysis has a monopoly of truth in the description of the phenomena of speech...traditional school grammar, TG grammar, ....all these and more can be shown to have their own particular relevance to the language teaching situation.' As cited in Meng, 2009

I agree to the second point of view. In my opinion, linguistics and language teaching are interactional with each other. In this paper, all the language teaching, teaching theories or language pedagogy refer to L2 teaching.

I find it helpful to think of linguistic form as if it were located in a pane of glass through which ideas are transmitted from speaker to listener. Under ordinary circumstances language users are not conscious of the glass itself, but only of the ideas that pass through it. The form of language is transparent, and it takes a special act of will to focus on the glass and not the ideas. Linguists undergo a training that teaches them how to focus on the glass ... the experience of becoming conscious of previously unconscious phenomena is one of the principal joys of linguistic work. (Chafe 1994, p.38)

Wallace Chafe's image of language as a pane of glass which linguists are trained to turn their attention on brings to mind another possible metaphor for thinking about the work of linguists.

Tom and Meriel Bloor (2004) provide an interesting parable when writing about terminology in linguistics; they ask us to imagine a dictator who prohibits all use of technical terms in garages, so those involved in motor vehicle maintenance would not be able to use terms such as 'reverse gear selector pivot pin' or even 'brake' for that matter.

Language and Linguistics are two different words that have to be used differently. A language is a mode of expression of thought by means of articulate sounds. But linguistics is a branch of study that deals with languages. It is a comparative study of languages. Hence it should be understood that linguistics Ural human languages are alike in their basic structural design; they are all instances of a single entity, human language (Aronoff, 2007).

Michael Halliday (2003) points out that "A language is a system of meaning- a semiotic system". Muharrem Ergin (1990) argues that "Language is a natural means to enable communication among people, a living entity that it has its own peculiar laws, by means of which alone can it develop, a system of contracts whose foundation was laid in times unknown, and a social institution interwoven with sounds".

Linguistic is a subject of study that is build on languages. Therefore it can be said that language is the fundamental unit of the branch of linguistics. In fact without languages the subject of linguistics cannot be there. Aron (2011) argues that linguistics studies the nature of languages, the various phonetic changes that take place in the languages, the changes in the meanings of particular words in the course of time and the like. A few laws have also been advocated by 
linguists who work on the languages. On the other hand each language has special and inherent characteristics. Since the languages are individual and separate in nature the need for their comparative study arose.

\section{LANGUAGE}

Language is an important organism in every human being and it separate human from other creature because human has the ability of learning and creates many sentences and words. Therefore, Language is a major attribute that distinguish human from the rest of the animal kingdom.

According to Merriam Webster Dictionary, language is system of conventional spoken or written symbols used by people in a shared culture to communicate with each other. A language reflects and affects both a culture's way of thinking, and changes in a culture influence the development of its language.

According to Derwing (1973) language is embedded in acts of communication and cannot be properly described and understood out of communicative contexts. This means that relevant "Language is a purely human and non-instinctive method of communicating ideas, emotions and desires by means of voluntarily produced symbols" (Edward Sapir, Harcourt, Brace and Company, 1921).

"Language, like culture, that other most human attribute, is notable for its unity in diversity: there are many languages and many cultures, all different but all fundamentally the same, because there is one human nature and because a fundamental property of this human nature is the way in which it allows such diversity in both language and culture" (Aronoff, 2007).

Bloch and Trager (1942) argues that "A language is a system of arbitrary vocal symbols by means of which a social gorup co-operate" Noam Chomsky (1957, p.13) argues that "language is innate, that crucial parts of the human language ability are built into the brain and are programmed into our genes".

Language diversity is attested from earliest recorded history. Therefore, language exist in a human being from birth and all person have the ability in acquiring language both verbally and nonverbally but the symbols and sign of languages in every culture and society are different. For example, sun in English and خورشيد in Persian have the same meaning but different form. So, in spite of the differences in sing and forms of languages, all languages have the same meaning.

\section{A. Yule's 5 Characteristics of Human Language}

\section{Displacement}

This is the ability to use language to talk about times, places and people other than the 'here and now'. It allows the user of language to talk about things and events not present in the immediate environments.

\section{Arbitrariness}

This means that there is generally no natural, inherent relationship between the signs (i.e. sounds or letters) we produce and their meaning. For this reason different languages can use different signs to refer to one and the same thing. e.g. a كin Persian is a flower in English.

Productivity

This is an important characteristic of human language allowing us to continuously create new utterances, combining the 'building bricks' of language in ever new ways, whether these be sounds, words or sentences.

\section{Cultural Transmission}

This refers to process whereby language is passed on from one generation to the next is described as cultural transmission. This means, for example, that a child born in Iran to Iranian parents but then adopted by English parents in England will tend to grow up speaking English as his/her first language and not Iranian. (unless the English parents make sure the child is also exposed to Iranian).

Duality

Duality (or 'double articulation') refers to two separate layers of language working together to provide us with a pool of sounds which we can combine to communicate with one another. On the one hand, there is a limited number of discrete sounds (e.g. the 44 phonemes in English) which in isolation have no inherent meaning e.g. $b, i$, or $n$. On the other hand there is unlimited number of distinct meanings which can create by combining these sounds in certain ways e.g. bin, or nib.

\section{B. Other Properties of Human Language}

Another feature of human language is reflexiveness, which means that human are able to use the language to talk about language - which is typically what linguists do. Discreteness is also something that is said to distinguish human languages from other forms of animal communication.

\section{LINGUISTICS}

According to Hudson (1999) "The history of linguistics, the study of language, is sometimes and reasonably dated from the first surviving descriptive grammar of a language of a European language, of Greek, written by Dionysius Thorax in about 100BC". 
The founder of modern structural linguistics was Ferdinand de Saussure (1857-1913), whose most influential work, Course in General Linguistics, was edited by his students and published in 1916. The pioneer linguist Ferdinand de Saussure criticized scholars who studied the history of a part of a language, dissociated from the whole to which it belongs. He insisted that linguists should study the complete system of a language at some point in time, and then examine how the entire system changes over time (R. M. W. Dixon).

A starting point can be Chomsky's list of the three main questions that linguistics should try to answer (Chomsky, 1986):

1) What constitutes knowledge of language? The goal is to discover the reality of language in the mind: what does a human being know who knows English, say? The linguist aims at describing the language contents of the human mind in whatever terms are appropriate, describing the full computational system that relates the physical reality of the actual sounds of speech to the cognitive representation of their meaning. The study of language knowledge in this sense has led to a massive explosion of work in the past ten years.

2) How is knowledge of language acquired? A mind must be able to learn any possible human language, not just English or Finnish, say. The process of acquisition enables and constrains the knowledge that is acquired; the study of language knowledge cannot be separated from the study of acquisition. This goal has led on the one hand to syntactic descriptions that take in acquisition, on the other to accounts of first language acquisition that take in recent linguistic descriptions, for instance the work of Radford (1990) and Atkinson (1992).

3) How is knowledge of language put to use? This acquired knowledge is used for sociological and psychological ends, whether to communicate ideas to people, to propose marriage to someone, to keep one's diary, to try to save the blue whale, or to achieve the innumerable other functions that human language may have.

Ferdinand de Saussure, a Swiss linguist considered to be the father of modern linguistics who studied variation in language. According to him there are diachronic linguistics and synchronic linguistics. As cited in Yule, 2006 diachronically linguistics studies how language change over time. The synchronic linguistic study language change in terms of differences within one language in different places and among different groups at the same time same time. Saussure viewed language as a system of signs, which consist of two parts: signified and signifier. The signified is the concept which is referred to, and the signifier is the label used for that concept.

Therefore, Saussure believe that, linguistics is the study of the system of a language in order to articulate elements which distinguish one functional form from another. What is of interest to linguists, in Saussure's view, is the system of forms, or langue as Saussure termed it, rather than parole, or the actual use of language by individual speakers. According to Saussure (1959) Langue refers to the "hoard deposited by the practice of speech in speakers who belong to the same community, a grammatical system which, to all intents and purposes, exists in the mind of each speaker". Also parole refers to what Chamsky called performance and langue refers to the concept of competence. Therefore, linguistic competence refers to what person knows and when he/she uses this knowledge in actual speech production, it is linguistic performance.

Chomsky later moved from the terms competence and performance to using the terms I-language and E-language (Chomsky 1986), I-language being the internal set of linguistic rules that children develop over their early years. Elanguage, or external language, is often incomplete and thought of as rather messy, especially in certain contexts such as informal conversation.

Linguistics is the science of language, including the sounds, words, and grammar rules. Words in languages are finite, but sentences are not. It is this creative aspect of human language that sets it apart from animal languages, which are essentially responses to stimuli. (Fromkin and Rodman).

"Linguistics will have to recognize laws operating universally in language, and in a strictly rational manner, separating general phenomena from those restricted to one branch of languages or another" (Saussure,1910-19).

There are many ways to study language scientifically. The most traditional, with its roots going back thousands of years to the Classical Greek and even Classical Sanskrit grammarians, is called Descriptive Linguistics. It is generally a descriptive discipline rather than a prescriptive one, which do not means that how to use a certain language, but rather concentrate on describing the rules which (especially native) speakers seem to have internalized. Apart from this, there are various different ways of 'doing' linguistics. For example, Diachronic linguistics looks at languages over a long period of time and generally compares different linguistic forms and uses across two different time periods, hence the name diachronic linguistics.

Synchronic is a term that comes from Greek meaning 'same time'. Modern linguistics, since the time of Saussure has devoted itself to a careful analysis of language situated or frozen within a particular time frame.

Linguistics is a science which can either be studied in a theoretical or a more applied way. For example, someone may be interested in finding out exactly how questions are formed in English (= theoretical). Once this is known the knowledge could be applied e.g. to language teaching, thereby (hopefully) enabling teachers and pupils to learn the language more effectively (Kortmann, 2005).

Within both descriptive and theoretical linguistics, historical linguistics refers to the study of how languages change over time. Sociolinguistics refers to interrelationship between sociology and linguistics. Psycholinguistics is the study of the psychological aspects of language. Lyons(1968) argues that "Linguistics is the scientific study of language by means of controlled and emprically verifiable observations with reference to some general theory of language structure". 
In fact there are two types of linguistics: Linguistic competence and Linguistic performance. Linguistic competence is the system of linguistic knowledge possessed by native speakers of a language. It is in contrast to the concept of Linguistic performance, the way the language system is used in communication.

Chomsky (1965) argues that "Linguistic theory is concerned primarily with an ideal speaker-listener, in a completely homogeneous speech-community, who knows it's (the speech community's) language perfectly and is unaffected by such grammatically irrelevant conditions as memory limitations, distractions, shifts of attention and interest, and errors (random or characteristic) in applying his knowledge of this language in actual performance".

Chomsky differentiates competence, which is an idealized capacity, from performance being the production of actual utterances. According to him, competence is the ideal speaker-hearer's knowledge of his or her language and it is the 'mental reality' which is responsible for all those aspects of language use which can be characterized as 'linguistic'.

The four branches of linguistics are phonology, morphology, syntax and semantics. Phonology deals with the study of sounds. Morphology deals with the the morphemes and combinations of morphemes as words. Syntax deals with the combinations of words as phrases and phrases as sentences. Finally semantics deals with the study of meaning of words, phrases and sentences. In fact, linguistic is the scientific or logical test of any aspect and property of language.

\section{DifFERENCES BETWEEn Linguistic AND LANGUAGE}

Languages that have a common source are genetically related. These languages were once dialects of the same language. According to Fromkin and Rodman (1993) "Earlier forms of Germanic languages, such as German, English, and Swedish were dialects of Proto-Germanic, while earlier forms of Romance languages, such as Spanish, French, and Italian were dialects of Latin".

There are linguistic changes like sound shift in the history of all languages, for example, the regular sound correspondences that exist between different stages of the same language, different dialects, and different languages. Words, morphemes, and phonemes may be changed, added or lost.

Fromkin and Rodman argue (1993) that "The study of linguistic change is called historical and comparative linguistics. Linguists identify regular sound correspondences using the comparative method among the cognates (words that developed from the same ancestral language) of related languages. They can restructure an earlier protolanguage and this allows linguists to determine the history of a language family". Linguistics is the scientific study of human language while language is a body of knowledge about speaking, reading or writing, in other words language is a way of communication between group of people. Therefore, most often the linguist' goal is to discover the" laws of human language".

Language and Linguistics are two different words that used for different purpose. A language is a mental phenomenon and a way of expression of thought by means of articulate sounds. On the other hand linguistics is a branch of study that deals with languages. According to Meng (2009) early in the years of Second World War, linguistics was recognized as an important component in language teaching theory. During the Second World War, America was in great need of soldiers knowing foreign languages. To meet this demand, a group of linguists including Bloomfield (1942) undertook to use the knowledge of linguistics to analyze the language to be taught and the result proved to be satisfactory. Bloomfield suggested that the only effective teacher should be the trained linguist working alongside the students, because language teachers often have an insufficient command of the language, only the trained linguists know how to guide the students learning from native speakers and how to teach the forms of the language.

Crystal (1992) on the other hand views language as," an act of speaking or writing in a given situation." This spoken or written form of language is referred to as, "parole or performance whereas the linguistic system underlying one's use of speech or writing is referred to as competence" (p.212).

Hence it should be understood that linguistics is a subject of study that is build on languages. Therefore it can be said that language is the fundamental unit of the branch of linguistics. Without languages the subject of linguistics cannot be there. In other words languages pave the way for the growth of the field of linguistics.

Linguistics studies the nature of languages, the various phonetic changes that take place in the languages, the changes in the meanings of particular words in the course of time and the like. A few laws have also been advocated by linguists who work on the languages.

Widdowson (1978) stressed the need that linguistics must be used selectively in language teaching, stating that "linguistics requires mediation of an interpreter for its own potential usefulness to the language teachers to be realized".

\section{CONCLUSION}

The outcome of the paper shows that linguistics is a field of study that examines language in a principled way. There are various theoretical perspectives that object of study can be analyzed, as language is multi-faceted; there are different idea and perspective to language. Therefore language and linguistic are different words and have different usage.

Language is a system of conventional spoken or written symbols used by people to communicate with each other, reflects a culture's way of thinking, and changes from one culture to another culture. Linguistic refer to scientific study of language. Also there is different point of view about language. 
Oller (1970) claimed that pragmatics has implications for language teaching; it defines the goal of teaching a language as prompting the students not merely to manipulate meaningless sound sequences, but to send and receive messages in the language. Many linguistics recognized the extent that languages are differ form each other, they also noted the extent that all languages have universal and common properties. These common properties called language universals.

Widdowson (1978) defined a set of contrasting concepts which distinguish language as a formal system and language use as communicative events. He advocated shifting the emphasis from teaching a second language as a formal system to teaching a second language as communication. Widdowson (1983) refers to the continuum between ELT and ESP teaching, we assert that there is a continuum between linguistics and language teaching (i.e. a continuum between language proficiency, language awareness and performance). This is the reason why we cannot isolate anything: grasping the linguistic phenomenon generally helps us to have a better command of the language, to be more aware of the language and to perform in the classroom more efficiently.

\section{REFERENCES}

[1] Aron. (2011). Difference between Language and Linguistics. http://wwwdifferencebetween.com. (accessed 30/2/2011).

[2] Aitchison, Jean. (1992). Teach yourself linguistics .Chicago: NTC Publishing.

[3] Aitchinson, M. (1992). Children's Syntax. Blackwell: Oxford.

[4] Bloch, Bernard; \& Trager, George L. (1942). Outline of linguistic analysis. Special publications of the Linguistic Society of America. Baltimore: Linguistic Society America.

[5] Bloomfield, L. (1942). Outline Guide for the Practical Study of Foreign Languages. Special Publications of the Linguistic Society of America. Baltimore: Linguistic Society of America.

[6] Bloor, Thomas and Bloor, Meriel. (2004). The Functional Analysis of English. Second Edition. London: Arnold.

[7] Chafe, Wallace. (1994). Discourse, Consciousness, and Time: The Flow and Displacement of consciousness in Speaking and Writting Chicago: The University of Chicago Press.

[8] Chomsky, Noam A. (1965). Aspects of the Theory of Syntax. Cambridge, MA: MIT Press.

[9] Chomsky, Noam A. (1957). Syntactic Structures, The Hague/Paris: Mouton

[10] Chomsky, Noam A. (1986). Knowledge of Language: Its Nature, Origin and Use. New York: Praeger.

[11] Chomsky, Noam A. (2006). Language and Mind. Third Edition. Cambridge: Cambridge University Press.

[12] Crystal, David. (1992). The Penguin dictionary of language, 2nd edition of the Encyclopedic dictionary (Harmondsworth: Penguin, 1999), vii+390 pp. 0140514163.

[13] De Saussure, Ferdinand. (1959). Course in General Linguistics. New York: McGraw-Hill Publishers.

[14] DeSaussure, Ferdinand. (1910-19). Cours de linguistique générale (French Edition). http:// www.amazon.com.

[15] Dixon R. M. W. (2009). Basic Linguistic Theory Volume 1: Methodology. Oxford University Press.

[16] Chomsky, Noam A. (1965). Aspects of the Theory of Syntax. Cambridge, MA: MIT.

[17] Derwing, Bruce L. (1973). Transformational Grammar as a Theory of Language Acquisition London: Cambridge University Press.

[18] Ergin, Muharrem. (1990). Retervied from abs.kafkas.edu.tr/upload/37/LANGUAGE.

[19] Finegan, Edward. (2004). Language: Its Structure and Use. Fort Worth: Harcourt Brace College Publishers. Ch. 1.

[20] Fromkin, Victoria and Rodman, Robert. (1993). An introduction to language. Fort Worth, TX: Harcourt Brace Jovanovich.

[21] Halliday, M.A.K. (2003). On Language and Linguistics, Jonathan Webster (ed.), Continuum International Publishing.

[22] Hudson, Govern. (1999). Essentional Introductory Linguistics: Oxford OX4 1JF, UK.

[23] Johnson, M. (1967). Definitions and models in curriculum theory. Educational Theory, 17:127-40.

[24] Kortmann, Bernd. (2005). English Linguistics: Essentials. Berlin: Cornelsen Verlag. Ch. 1.

[25] Lado, R. (1957). Linguistics across Cultures. University of Michigan Press.

[26] Lamendella, J.T. (1969). On the irrelelevance of transformational grammar to second language pedagogy. Language Learning, 19:255-70.

[27] Levenson, E.A. (1979). Second language lexical acquisition: issues and problems. Interlanguage Studies Bulletin, 4:147-60.

[28] Lyons, John (1968). Introduction to Theoretical Linguistics.London: Camberige University Press of Conscious Experience in Speaking and Writing. Chicago, IL: University of Press.

[29] Meng, Jing (2009). The Relationship between Linguistics and Language Teaching: Asian Social Science. Vol. 5, No. 12: College of foreign languages, Qingdao University of Science and Technology Qingdao 266061, China.

[30] Oller, J.W. (1970). Transformational theory and pragmatics. Modern Language Journal, 54:504-507.

[31] Radford, A. (1990). Syntactic Theory and the Acquisition of English Syntax: the Nature of Early Grammars in English. Oxford: Blackwell University Press.

[32] Sapir, E. (1921). Language: An Introduction to the study of speech. New York: Harcourt, Brace.

[33] Vlack, Stephen. (2009). Introduction to Linguistics, English Education MA.

[34] Widdowson, H.G. (1983). Learning Purpose and Language Use, Oxford: Oxford University Press.

[35] Widdowson, H.G. (1978). Teaching Language as Communication. Oxford: Oxford University Press.

[36] Yule, George. (2006). The Study of Language: An Introduction. Cambridge: Cambridge University Press. 


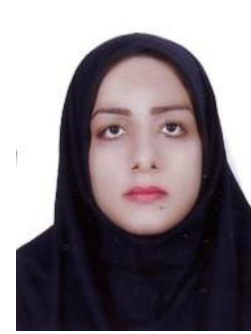

Hajar Shahhoseiny was born in Iran. She is an M.A in TEFL. She received her M.A in TEFL from Bushehr Islamic Azad University Branch of Science and Research in Iran.

Mrs. Shahhoseiny writes an article (about "written errors of EFL learners"), and punished one book with title of "A Linguistic Study of Errors". 